https://www.journal-imab-bg.org

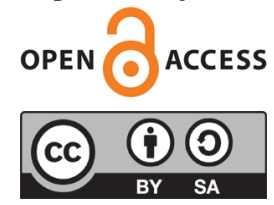

Original article

\title{
LONG-TERM MODEL AND MONTE CARLO SIMULATION OF THE PUBLIC HEALTH EXPENDITURE IN BULGARIA
}

\author{
Nikolay Atanasov \\ Department of Health Management and Health Economics, Faculty of Public \\ Health, Medical University Plovdiv, Bulgaria.
}

\begin{abstract}
Purpose: The aim of the study is to build a longterm model and conduct a Monte Carlo simulation of the public health expenditure (PHE) of Bulgaria with the gross domestic product (GDP) as an independent variable.

Material/Methods: Statistical models are used for modeling the long-term dependence between the macroeconomic dynamic rows, testing of hypotheses of stationarity (Augmented Dickey-Fuller tests), for serial autocorrelation and others.

Results: There is a well-defined, statistically significant long-term relationship between public health expenditure and gross domestic product. The long-term model of health expenditure has an estimate of the cointegration constant of 1.023 (p-value < 0.05). Monte Carlo simulations are presented with 1000,2000 and 3000 experiments, generated based on the normal distribution of the input variable.

Conclusions: In the period after the year 1990, a well-defined long-term relationship between public health expenditure and GDP exists. The Monte Carlo simulation can be regarded as a reliable instrument for studying the most likely fluctuations in health expenditure caused by the GDP.
\end{abstract}

Keywords: health expenditure, Monte Carlo simulation, cointegration, health policy,

\section{INTRODUCTION}

Public health expenditure (PHE) can be defined as a complex set of funds, which public authorities - government bodies and institutions spend in the health care system. The purpose of public expenditure is primarily a full or partial reimbursement of the operating and, in certain cases, investment costs of health care providers and in addition to implement and finance policies and their realization in the field of disease prevention, promotion and screening. In the case of Bulgaria, in the presence of a public insurance model and striving to ensure universal coverage, public health expenditure is financed by two sources. These are the budget of the public health insurer and the government budget. After the introduction of the insurance model of financing, the share of funds from the state budget dropped to about $9-10 \%$ of total health expendi- ture, i.e., the insurer plays a major role in public funding.

Regardless of the specific features of the health care system, the gross domestic product predetermines the possibilities for financing public expenditure. Many macroeconomic variables, such as consumption, employment, unemployment, wage levels, budget revenue, expenditure, on the one hand, and GDP, on the other, are found to be interconnected and cointegrated in the long-term.

Cointegration is a property of dynamic rows, in which they are integrated of the same order " $d$ ", and their linear model provides residuals integrated of the order " $\mathrm{d}$ 1 ". It is considered that a time variable is integrated of the order " $d$ " if by applying differences of the same order it acquires the property of stationarity (mean and dispersion of the time series remain constant over time). [1,2]

The Monte Carlo method is accepted and has been established over time as a good basis for studying uncertainty and risk. It is used in various scientific fields - initially in physics, later in investment theory, epidemiology, genetics and others.

The purpose of the present study is to estimate the fluctuation or changes in the public health expenditure of Bulgaria, determined by GDP through Monte Carlo simulations. It covers the period after the year 1990 until 2019. This requires the solution of two tasks. The first is related to the derivation of a long-term expenditure model, and the second is regarding the actual conduct of the experiments.

\section{MATERIALS AND METHODS}

The dynamic row of public health expenditure is presented on a consolidated basis (government, National Health Insurance Fund - NHIF and municipalities), and its values are obtained from the following sources:

- for the period 1990-1997 "Statistical Yearbook", issued by the National Statistical Institute [3];

- the values after the year 1997 are from the consolidated fiscal program for the period 1998-2019 from the Ministry of Finance [4].

The dynamic row of GDP is constructed from the internet portal of the National Statistical Institute of Bulgaria - Information System INFOSTAT [5].

The values in the two rows until the year 1997 are recalculated by the author in denominated Bulgarian levs. 
The following analytical methods are used in the present study:

- Ordinary Least Square (OLS) regression analysis;

- Box-Pierce Q statistics tests for determining autocorrelation;

- Differencing for overcoming autocorrelation;

- Augmented Dickey-Fuller (ADF) test for testing the hypothesis of a unit root;

- Graphic representation of natural logarithm transformation of the values of output rows;

- Random number generation.

All statistical tests are conducted in the condition of a $5 \%$ level of significance.

\section{RESULTS}

Brief presentation of the general health expenditure and its elements

Typically, public expenditure in health care is significant, predominant in volume in the total expenditure of the health care system. Although private expenditure has seen a higher growth rate since 2003 (their growth indices are $223 \%$ compared to $196 \%$ for public expenditure), those of public institutions are dominant. Figure 1 illustrates the dynamics of total health care expenditure and their two main components - public and private.

Fig. 1. Total public and private health expenditure after the year 2003 (the figure was created by the author from data taken from the National Statistical Institute of Bulgaria and Eurostat).

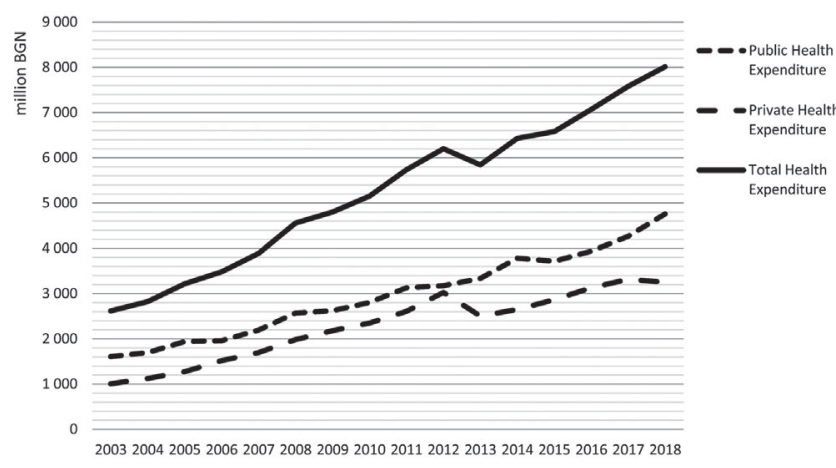

On the other hand, the weight of public in total expenditure varies from $51 \%$ to $61 \%$ and apparently does not have a clearly visible trend. Rather, their share gradually shrank from just over $60 \%$ in 2003 to $51 \%$ in 2012 . Its average level after the year 2003 was $57 \%$ and subsequently began to grow with fluctuations. Over the last eight years, public expenditure has regained their relative weight in total health expenditure to around $60 \%$ (fig. 2).
Fig. 2. The relative weight of public health expenditure.

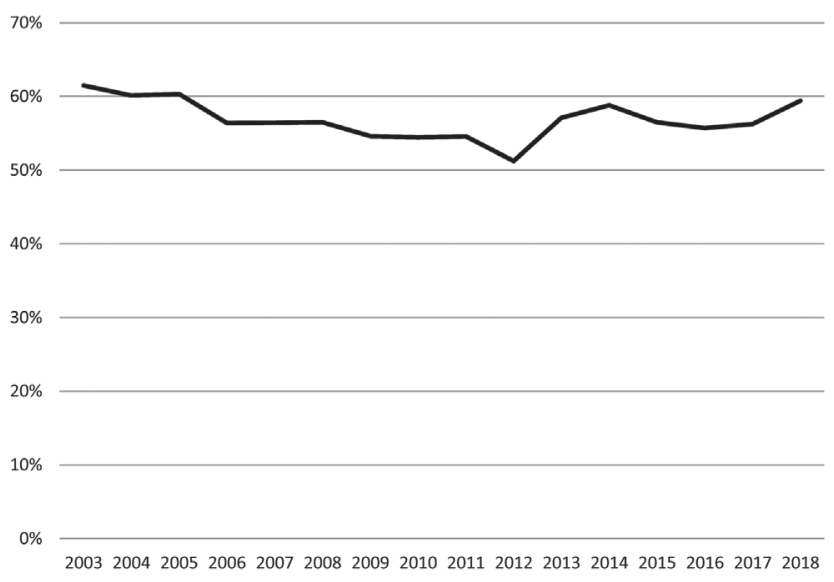

The dominance of public sources for financing the health care system is a natural reflection of the fact that although medical services are divisible goods and the benefits of their consumption can be individualized; there are also significant positive externalities that extend to the whole society.

Building a model of a long-term relationship between PHE and GDP.

The first step in the detailed study of long-term dependence is to construct the two dynamic rows. The natural logarithm values of public health expenditure and GDP for the period 1990-2019 are shown below (fig. 3).

Fig. 3. Natural logarithms of the public health expenditure and the nominal GDP for the period 1990-2019.

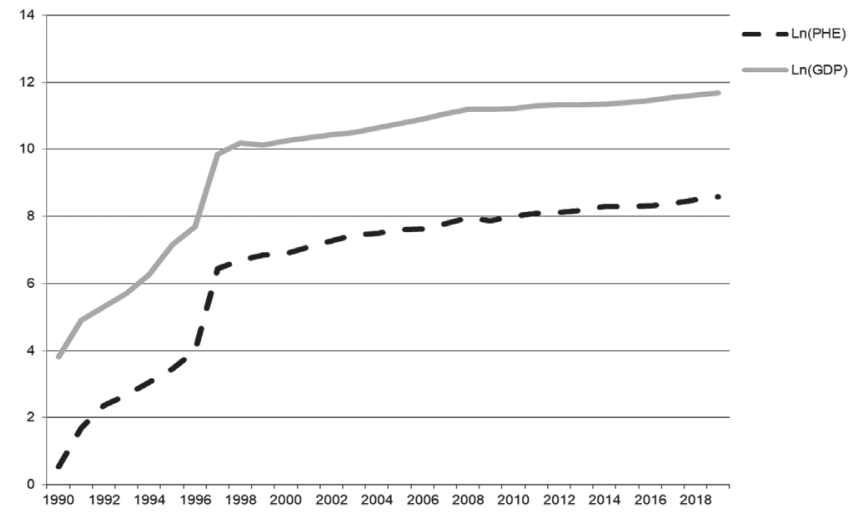

Time trend functions fitted by straight lines have the following numerical characteristics:

PHE $=0.232 t+2.917$

with $R^{2}=0.754$

and

$\mathrm{GDP}=0.226 \mathrm{t}+6.252$

with $\mathrm{R}^{2}=0.728$

The slope coefficient in the time trend function of PHE is slightly higher than the one in GDP. This fact can 
explain the relatively faster increase in expenditure over time compared to GDP.

The autocorrelation coefficients for the first seven lags of the two rows can be seen in the following table. In all cases, they are statistically significant and assume high, considerably greater values.

Table 1. Autocorrelation coefficients of the dynamic rows.

\begin{tabular}{|c|c|c|}
\hline \multirow{2}{*}{$\begin{array}{c}\text { Time } \\
\text { lag }\end{array}$} & \multicolumn{2}{|c|}{ Autocorrelation coefficients (ACC) } \\
\cline { 2 - 3 } & Ln(PHE) & Ln(GDP) \\
\hline 1 & 0.975 & 0.978 \\
\hline 2 & 0.926 & 0.931 \\
\hline 3 & 0.857 & 0.853 \\
\hline 4 & 0.76 & 0.735 \\
\hline 5 & 0.627 & 0.575 \\
\hline 6 & 0.445 & 0.394 \\
\hline 7 & 0.208 & 0.178 \\
\hline
\end{tabular}

There is a strong autocorrelation in both dynamic rows - a result expected for macroeconomic variables. Figure 3 clearly shows the presence of a trend in the development of the variables over time. For these reasons, it can be expected that both rows will not be stationary.

The Augmented Dickey-Fuller test is applied to verify the hypothesis of stationarity of the initial dynamic rows. The unit root test is based on an auxiliary model with a one-year lagged variable, with time, as independent variables and a constant. For both dynamic rows, the test models are as follows:

$\operatorname{Ln}(P H E)_{t}-\operatorname{Ln}(P H E)_{t-1}=\beta_{0}+\beta_{1} \cdot \operatorname{Ln}(P H E) t-1+\beta_{2} \cdot\left[\operatorname{Ln}(P H E)_{t-1}-\right.$ $\operatorname{Ln}(\mathrm{PHE}) \mathrm{t}-2]+\beta_{3} . t+\mathrm{e}_{\mathrm{t}}$

$\operatorname{Ln}(G D P) t-\operatorname{Ln}(G D P)_{t-1}=\beta_{0}+\beta_{1} \cdot \operatorname{Ln}(G D P)_{t-1}+\beta_{2} \cdot\left[\operatorname{Ln}(G D P)_{t-1}-\right.$ $\operatorname{Ln}(G D P) t-2]+\beta_{3 . t}+e_{t}$

The reason for choosing such an auxiliary model is that the values of the rows follow an upward trend. In addition, the mean around which observations fluctuate is different from zero (fig. 3).

It is obtained the following OLS estimates of the models (the value of the t-statistics is indicated in parentheses):

$$
\begin{aligned}
& \operatorname{Ln}(\mathrm{PHE})_{\mathrm{t}}-\mathrm{Ln}(\mathrm{PHE})_{\mathrm{t}-1}=1.03-0.13 \operatorname{Ln}(\mathrm{PHE})_{\mathrm{t}-1}+0.04\left[\mathrm{Ln}(\mathrm{PHE})_{\mathrm{t}-1}\right. \\
& \quad(3.169)(-1.777) \\
& -\operatorname{Ln}(\mathrm{PHE})_{\mathrm{t}-2]+0.01 \mathrm{t}+\mathrm{e}_{\mathrm{t}}}
\end{aligned}
$$$$
(0.284)
$$

$$
\begin{gathered}
\operatorname{Ln}(G D P) t-\operatorname{Ln}(G D P)_{t-1}=1.33-0.11 \operatorname{Ln}(G D P)_{t-1}+0.08\left[\operatorname{Ln}(G D P)_{t-1}\right. \\
(2.811)(-1.753) \\
\left.-\operatorname{Ln}(G D P)_{t-2}\right]+0.001 t+e_{t}
\end{gathered}
$$$$
\text { (0.035) }
$$

For the initial rows of PHE and GDP, the null hypothesis of the existence of a unit root cannot be rejected because the t-statistics of the coefficient estimates before the lagged variable $\beta_{1}(-1.777$ and -1.753 , respectively) is smaller in absolute value than of the accepted critical value within the test. In the case of an auxiliary model with a variable and a trend at a 5\% significance level, the limit value is -3.40 , and at $10 \%$, it is -3.13 . The Augmented Dickey-Fuller test confirms that the initial rows of public health expenditure and GDP are not stationary ( $\mathrm{p}$-value $>$ $0.05)$.

In order to achieve stationarity, the trend in the rows should be eliminated. This is realized by applying first-order differences. Figure 4 shows the transformed dynamic rows, $\Delta \mathrm{Ln}(\mathrm{PHE})$ and $\Delta \mathrm{Ln}(\mathrm{GDP})$, respectively.

Fig. 4. First-order differences of public health expenditure and GDP.

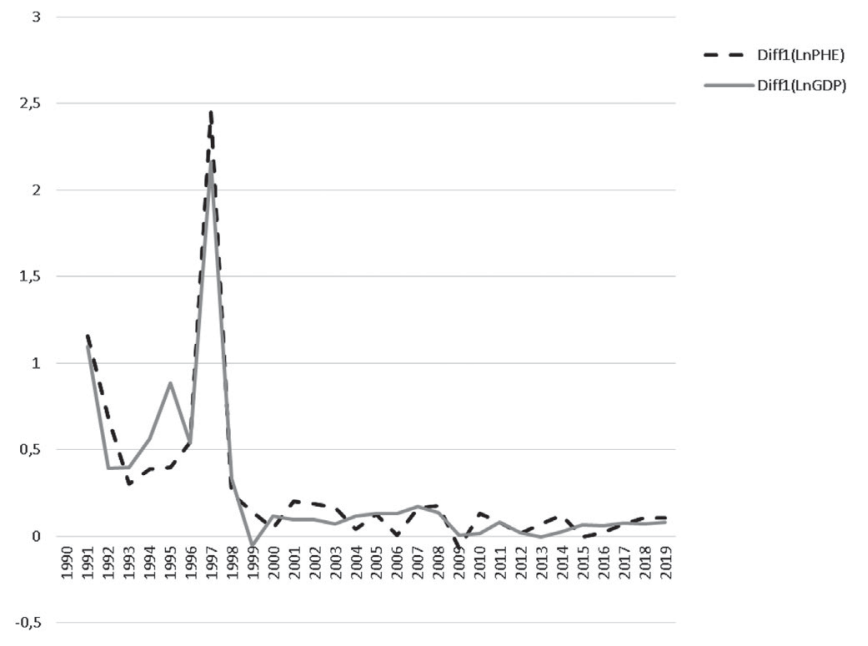

The dynamic rows consisting of first-order differences do not contain a visible trend and are not autocorrelated - the Box-Pierce statistics for the first lag allows us to accept the hypothesis of independence of the members of the rows. For the dynamic row of the health expenditure, it assumes the values Q $(1)=1.78$ (p-value $>0.05)$, and for GDP, respectively, Q $(1)=3.15$ ( $\mathrm{p}$-value $>0.05$ ). The means of the differenced rows are close to zero, especially if the values up to the year 1998 are ignored.

The lack of a trend and the presence of a mean close to zero allows stationary tests to be performed with an auxiliary model without a constant $\left(\beta_{0}\right)$ and without time $(t)$ as an independent variable. The OLS estimates of the regression models, already on the basis of the rows with differences of the first order, take the form:

$$
\begin{aligned}
& \operatorname{Ln}(P H E)_{t}-\operatorname{Ln}(P H E)_{t-1}=-0.536 \operatorname{Ln}(P H E)_{t-1}-0.171\left[\operatorname{Ln}(P H E)_{t-1}\right. \\
& (-2.691) \quad(-0.9489) \\
& -\operatorname{Ln}(\mathrm{PHE}) \mathrm{t}-2]+\mathrm{e}_{\mathrm{t}}
\end{aligned}
$$

$$
\begin{aligned}
& \operatorname{Ln}(G D P)_{t}-\operatorname{Ln}(G D P)_{t-1}= \\
& -0.38 \operatorname{Ln}(G D P) t-1-0.269\left[\operatorname{Ln}(G D P)_{t-1}\right. \\
& \left.-\operatorname{Ln}(G D P)_{t-2}\right]+e_{t}
\end{aligned}
$$


The rows composed of first-order differences pass the stationarity tests ( $t$-criterion, as an assessment of the level of significance of the coefficient of the lagged variables, assumes higher absolute values than the critical levels ($2.691<-1.93$ and $-2.115<-1.93$, p-value $<0.05$ at $5 \%$ significance level). On this basis, the alternative hypothesis can be accepted that the rows with first-order differences represent a stationary process with a mean close to zero and a variance constant in time. Therefore, both dynamic rows - public health expenditure and GDP - are integrated from the same - first-order, i.e. they are of type I (1). This result is essential for the long-term relationship and the likely cointegration.

The first condition for confirming the cointegration hypothesis is present - public health expenditure and GDP are of type I (1). To verify the second condition (their linear regression model to have residuals integrated in order of magnitude lower by one unit, i.e., to be of type I (0)), it is necessary to construct the cointegration model with the following form:

$\Delta \mathrm{Ln}(\mathrm{PHE})=\lambda_{0}+\lambda_{1} . \Delta \mathrm{Ln}(\mathrm{GDP})+\mathrm{u}_{\mathrm{t}}$

The OLS estimates of a slope coefficient and a constant can be seen on eqation (10):

$$
\Delta \mathrm{Ln}(\mathrm{PHE})=\underset{(0.01)}{0.0003+1.023 . \Delta \mathrm{Ln}(\mathrm{GDP})+\mathrm{u}_{\mathrm{t}}}
$$

The overall test $(\mathrm{F}(1 ; 27)=275.49(\mathrm{p}$-value $<0.05)$, $\left.\mathrm{R}^{2}=0.911\right)$ proves that there is a significant relationship between the public health expenditure and GDP. The regression coefficient before GDP is also significant ( $\mathrm{t}$-value $=16.598 ; \mathrm{p}$-value <0.05). The residuals are not autocorrelated $(\mathrm{Q}(1)=0.16$; p-value $>0.05)$ and their mean is close to zero $\left(\mu=-9,57 \cdot 10^{-18}\right)$. The dynamic of the residuals is presented on the next figure.

Fig. 5. Residuals " $\mathrm{u}_{\mathrm{t}}$ "from the cointegration model (equation 10) of public health expenditure.

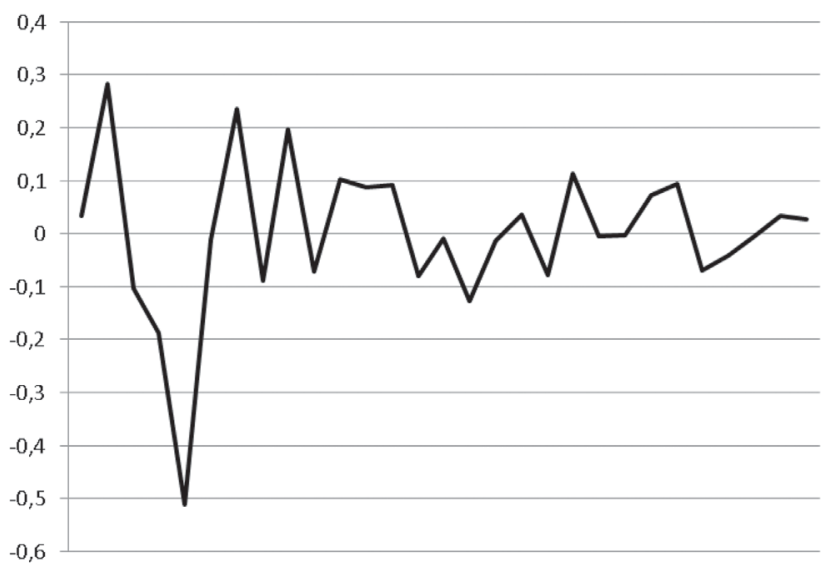

The Augmented Dickey-Fuller test with an auxiliary model without a constant and time as an independent variable confirms the presence of a stationary process in the residuals row ( $\mathrm{t}$-value $=-4.083<-1.93$ at a $5 \%$ significance level), i.e. they are of type I (0). Therefore, PHE and GDP are cointegrated with a cointegration constant $\lambda_{1}=1.023$, or in the long run, one percent change in $\Delta \operatorname{Ln}(\mathrm{GDP})$ would cause a change of 1.023 percent in the level of $\Delta \mathrm{Ln}(\mathrm{PHE})$.

\section{Conducting Monte Carlo simulations.}

A prerequisite for simulating the values of a variable to study its behavior is the presence of a determined relationship between the variable itself and another in the role of the predictor. An important point in the application of the method is the generation of a certain number of random values that mimic the role of an input variable in conducting the simulations with a model from equation 10 . The type of empirical distribution of the independent variable needs to be considered when generating random numbers. [6] Each simulation of the resulting variable is based on a certain number of experiments (n). Within this study, three simulations were performed, with 1 000, 2 000, and 3000 trials, respectively. Thus, the same number of values of public health expenditure is modeled with randomly generated values of $\Delta \mathrm{Ln}(\mathrm{GDP})$.

The distribution of the independent variable $\Delta \mathrm{Ln}(\mathrm{GDP})$ is not normal $(\mathrm{N}=29$; Shapiro-Wilk $=0.609$; Sig. <0.05). Figures 6 and 7 illustrate the empirical distribution of the independent variable.

Fig. 6. Histogram of $\Delta \operatorname{Ln}(\mathrm{GDP})$.

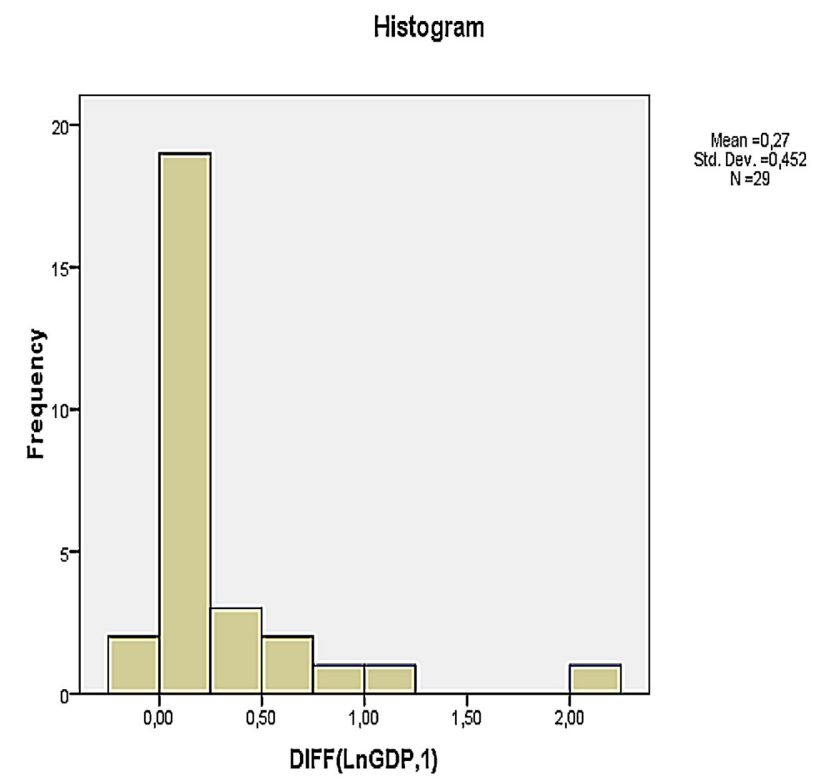


Fig. 7. Normal Q-Q plot of $\Delta \operatorname{Ln}(\mathrm{GDP})$.

\section{Normal Q-Q Plot of DIFF(LnGDP,1)}

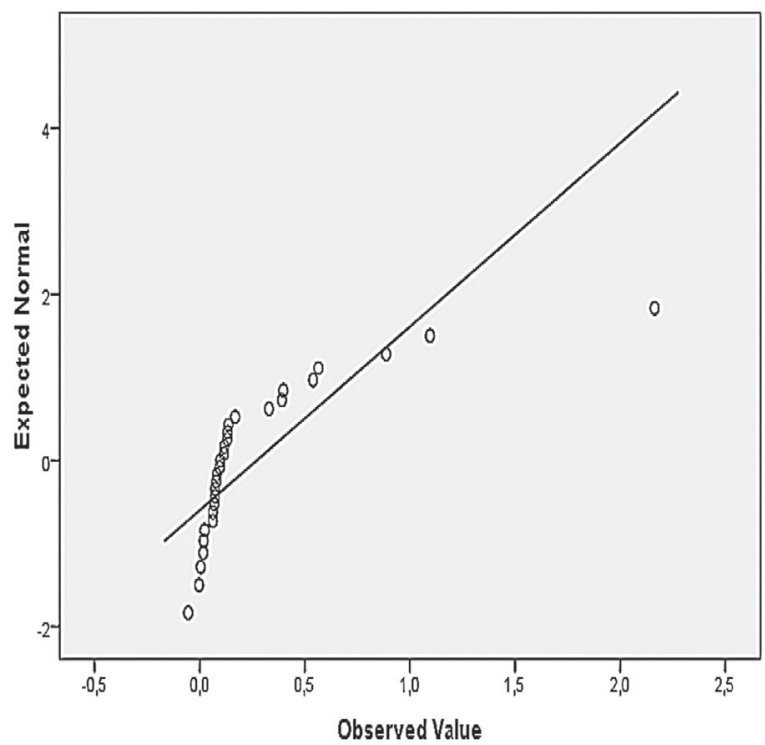

The reason for observing a distribution far from normal lies in the relatively large number of cases of significant fluctuations in nominal GDP during the first eight years of the observed period (years 1990-1997). If the first eight observations of GDP are excluded, i.e. shortening the period between the years 1998 and 2019, we will obtain an empirical model of distribution close to normal ( $\mathrm{N}=21$; Shapiro-Wilk =0.971; Sig.> 0.05). The next two figures show the frequency distribution and Q-Q plot. 2019.

Fig. 8. Histogram of $\Delta \operatorname{Ln}(\mathrm{GDP})$ for the period 1998

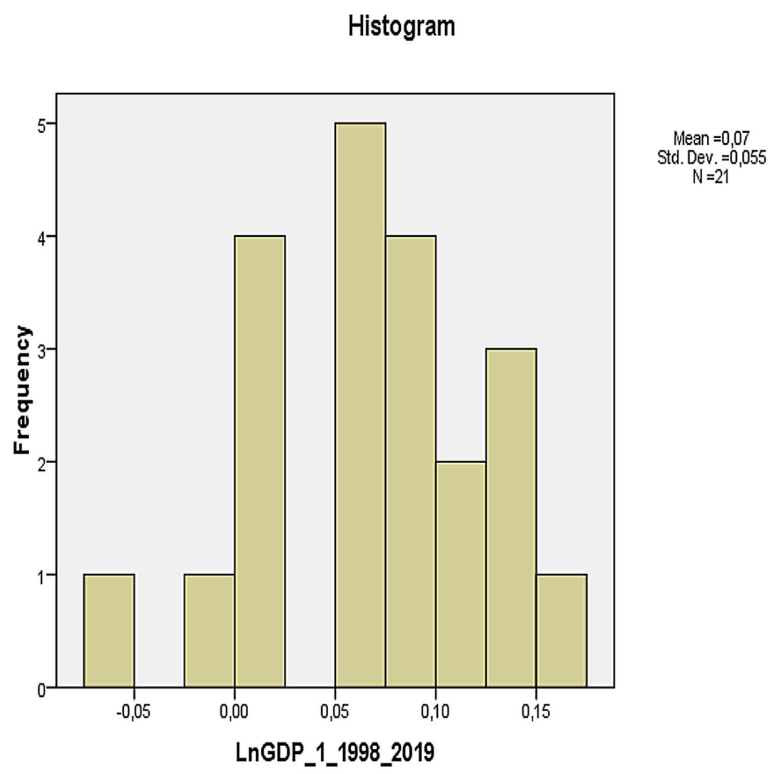


If we turn our attention to Figure 1, it could be assumed that overall health expenditure is likely to continue to rise in absolute terms. This is an unchanging trend, firmly established since the first years of the new century. In fact, the beginning of this trend coincides with the transition from budget funding to the insurance model of the national health system. However, this trend is mainly due to the growth of the country's nominal GDP. It is difficult to be convinced without new research that institutional reforms have put significant pressure on spending growth.

An interesting trend, that has formed in the last few years, is the faster growth of PHE (Fig. 1 and Fig. 2). This fact can be explained with the attempts of the health authorities to limit the direct payments' adverse effects. Another fundamental factor that is sure to have an impact on the growth rate of public funding in the near future is the global Covid 19 pandemic.

In the context of the relationship with the income, it could be expected that in the future we can see a faster increase in expenditure than in GDP. There is also a definite predominance of the fluctuation of public health expenditure over that of GDP $\left(\mathrm{SD}_{\Delta \mathrm{Ln}(\mathrm{PHE})}=0.485 ; \mathrm{SD} \Delta \mathrm{Ln}(\mathrm{GDP})\right.$ $=0.452$ ). An additional impact in this direction will most likely be due to the new costs caused by Covid 19, covered by the public funds. As a result of these factors, such as the pandemic and the probable intention to limit direct payments, it is quite likely that in the future public funding for health care will fluctuate within considerable limits, including their burden. This is shown by the results of the Monte Carlo simulations (Table 2). Taking into account the greater than one unit of income elasticity (equation 10) in conjunction with the other results, we could define public health expenditures as rather a luxury good. This assertion most likely also applies to general health expenditure, but should be confirmed by further results.

\section{DISCUSSION}

This paper treats the empirical buildind of a public health expenditure's long-term model with independent variable GDP, subsequent Monte Carlo experiments to assess its fluctuations and burden.

The link between health expenditure (HE) and macroeconomic dynamics is actually emerging as one of the problems which increase the importance of health economics and policy. Each study of health expenditure with an aspect of financing or relations with GDP uses its own methodology and format of data; thus, direct comparisons between different results are at high risk of inaccuracies. However, the results from some recent research on the subject could serve as a debate on the results obtained in this article.

The problem finds a place in the framework of international comparative analyzes, initially and above all for the OECD countries. According to Gerdtham and Jönsson (2000) the early research of Hansen and King from 1996 found that for 20 OECD countries for the period 19601987 could not be rejected in both time series (HE and GDP) the hypothesis of unit root, using ADF test. The hypothesis of no-cointegration was also rejected. Analogical study of Blomqvist and Carter (1997) for 18 OECD countries for the period 1960-1991 presented confirming results but using a model of health expenditure with GDP and time trend. $[7,8,9]$ A more recent study of Gerdtham and Löthgrenwith with data between 1960 and 1997 shows that the hypothesis of unit root is rejected for only two OECD countries Portugal and Switzerland. The HE and GDP series was characterized as $\mathrm{I}(1)$ processes. Panel cointegration test proved that health expenditure and GDP for OECD countries was contegrated. [10] The present study found similar results with the same instruments and time series with almost equal length. It is found a unit root in the initial time series and it was overcome with differencing, i.e. the series are of type I(1). The additional tests confirm that they are cointegrated.

The study of Mehrara, Musai, and Amiri (2010) based on the Panel Smooth Threshold Regression (PSTR) found that the income elasticity of HE of all OECD countries was estimated at about 2.59 mutch more than unity and conclude that health expenditure can be classified as a luxury good (for dataset 1993-2007). The authors used a linear model of real HE per capita with real per capita income as an independent variable. [11] The present study for Bulgaria shows that the income elasticity of PHE is 1.023 and it is determined on the basis of nominal and not per capita values of PHE and GDP. With another format, real and per capita data, as well as with general health expenditure, we would expect different results about income elasticity. One of the latest studies on the subject area in the United States and Canada reached similar values of income elasticity (0.92) to those of public expenditure on health in Bulgaria from the present paper. [12] The new research for OECD countries for the period 1988-2012 and using VECM methodology found that in long term a $1 \%$ increase in the GDP is associated with a $1.1 \%$ increase in health care spending.[13] This finding is very close to the results of the proposed paper even with some methodological differences.

The existence of a stationary process in the dynamics of health expenditure for the same countries for a long period of time, but taking into account structural changes/ shocks is also of interest on the topic. [14] The case of Bulgaria with its economic trends in the beginning and the middle of the nineties of the last century is very interesting and additional studies are needed to be confirmed or rejected potential structural changes. The likely structural changes in 1997 will necessitate a revision of the empirical characteristics of the long-term model. Finding an answer to this question requires additional tests and modeling.

A study focused on the financing of public expenditure on health care in India, in the context of differences between states and possibilities to achieve universal coverage, shows a well-defined long-term relationship using GDP and tax revenues per capita as predictors. [15] The same study shows that a one percent increase in GDP per capita leads to an increase of 0.42 percent of public health expenditure per capita. The elasticity of public health expenditure to GDP per capita was found to be 0.53 in sixteen major Indian states surveyed with panel data analysis.

Like the present paper methodology, research for Turkey establishes a long-term relationship between health 
expenditure (public, private and general) and GDP. [16] The "health-led growth hypothesis" occupies an interesting place in the study of health expenditure, and research in this regard has also been completed for Turkey. [17]

Besides, the relationship with economic growth and dynamics of GDP health expenditure are considered in the context of environmental pollution and energy consumption, which is a new direction in this subject area. Some of the studies in this group arrive at results relevant to those in this article. With the help of VECM Granger causality analysis, it is established that there is a statistically significant shortterm and long-term causal relationship between health expenditure and economic growth in the OECD countries for the period 1992-2014. In fact, it is accepted the hypothesis that health expenditure provides part of economic growth or led to growth in developed countries. [18]. In a methodologically similar analysis, Haseeb et al. present some different results for ASEAN countries. Each of the independent variables, GDP, energy consumption, $\mathrm{CO} 2$ emissions, and R\&D expenditure, has a significant causality impact on the health expenditure. But on the other hand, when the direction of the casual relationship changes, health expenditure do not appear to have a significant impact on economic growth and other variables. [19]

An interesting fact is that according to a previous study (Atanasov, 2012) for Bulgaria with similar tools but with shorter dynamic rows (1990-2010), a lower level of the cointegration constant was obtained - less than one (0.904). The comparison with present results proves that for the last ten years, public expenditure on health care has become relatively more sensitive or elastic to changes in the GDP.

\section{CONCLUSIONS}

The study of the elasticity of health expenditure through simulations and modeling of their response to probable fluctuations in income using the Monte Carlo simulation allows a deeper insight into their nature and especially their relationship to macroeconomic processes and dynamics. Moreover, simulating probable expenditure fluctuations provides an assessment of the uncertainty of their increase in periods of declining income and recession.

Quantitative estimates of income elasticity of health expenditure from the present study provide results that could be considered from the financing policy of health care in conditions of growing funds. It could exist and another point of view, the increased weight of public health expenditure in recent years could be explained as an expected result on the background of overcoming adverse effects of the highest direct patient payments proportion compared to the countries of the Balkan region and the European Union.

\section{REFERENCES:}

1. Dougherty C. Introduction to Econometrics. 4th Edition. Oxford University Press. April 30, 2011. p.463. [Internet]

2. Watsham TJ, Parramore K. Quantitative Methods in Finance. 1st edition. Cengage Learning EMEA. December 19, 1996: pp.248-257. [Internet]

3. Statistical Yarbook of the Republic of Bulgaria, Chapter: Government Financial Statistic. [in Bulgarian] National Statistical Institute, Sofia, 1991, 1992,1993, 1994, 1995, 1996, 1997, 1998.

4. Data on the Consolidated Fiscal Program (annual) - Expenditure by Functions (1998-2019). Ministry of Finance - R. Bulgaria. December 3, 2020.

5. Report result (nsi.bg); seen on December 3, 2020.

6. Watsham TJ, Parramore K. Quantitative Methods in Finance. 1st edition. Cengage Learning EMEA. December 19, 1996: pp.308-312. [Internet]

7. Gerdtham UG, Jönsson B. Chapter 1 - International Comparisons of Health Expenditure: Theory, Data and
Econometric Analysis. Handbook of Health Economics. Volume 1, Part A, 2000. Pages 11-53. [Crossref]

8. Hansen P, King A. The determinants of health care expenditure: a cointegration approach. J Health Econ. 1996 Feb;15(1):127-137. [Crossref]

9. Blomqvist AG, Carter RAL. Is health care really a luxury? J Health Econ. 1997 Apr;16(2):207-229. [Crossref]

10. Gerdtham UG, Löthgren M. On stationarity and cointegration of international health expenditure and GDP. J Health Econ. 2000 Jul;19(4):461-75. [PubMed]

11. Mehrara M, Musai M, Amiri H. The Relationship between Health Expenditure and GDP in OECD Countries Using PSTR. Eur J Econ Fin Admin Sci. 2010 Sep;24:50-58.

12. Murthy VNR, Okunade AA. Determinants of U.S. health expenditure: Evidence from autoregressive distributed lag (ARDL) approach to cointegration. Economic Modelling. 2016 Dec;59:67-73. [Crossref]

13. Feng Y, Watt T, Charlesworth A,
Marsden G, Roberts A, Sussex J. What Determines the Health Care Expenditure of High Income Countries? A Dynamic Estimation. Appl Financial Econ. 2017 Nov;4(6):1-16. [Crossref]

14. Jewell T, Lee J, Tieslau M, Strazicich MC. Stationarity of health expenditures and GDP: evidence from panel unit root tests with heterogeneous structural breaks. J Health Econ. 2003 Mar;22(2):313-23. [PubMed]

15. Behera DK, Dash U. Impact of GDP and tax revenue on health care financing: An empirical investigation from Indian states. Theoretical \& Applied Economics. 2017 Summer;24(2(611):249-266. [Internet]

16. Sülkü SN, Caner A. Health care expenditures and gross domestic product: the Turkish case. Eur J Health Econ. 2011 Feb;12(1):29-38. [PubMed]

17. Atilgan E, Kilic D, Ertugrul HM. The dynamic relationship between health expenditure and economic growth: is the health-led growth hypothesis valid for Turkey? Eur J Health Econ. 2017 Jun;18(5):567-574. [PubMed] 
18. Gövdeli T. Health Expenditure, Economic Growth, and CO2 Emissions: Evidence from The OECD Countries. Adiyaman Üniversitesi Sosyal Bilimler Enstitüsü Dergisi. 2019 Mar;11(31):488-516. [Crossref]
19. Haseeb M, Kot S, Hussain HI, Jermsittiparsert K. Impact of Economic Growth, Environmental Pollution, and Energy Consumption on Health Expenditure and R\&D Expenditure of ASEAN Countries. Energies. 2019; 12(19):3598. [Crossref]

Please cite this article as: Atanasov N. Long-Term Model and Monte Carlo Simulation of the Public Health Expenditure in Bulgaria. J of IMAB. 2021 Jul-Sep;27(3):3911-3918. DOI: https://doi.org/10.5272/jimab.2021273.3911

Received: 12/02/2021; Published online: 02/09/2021

Address for correspondence:

Nikolay Georgiev Atanasov

Department of Health Management and Health Economics, Faculty of Public Health, Medical University Plovdiv,

15A, bul. Vasil Aprilov, Plovdiv, 4000, Bulgaria;

E-mail: nik.atanasov@abv.bg, 